\title{
基于政治学科核心素养的“学本”课堂设计 一以《新时代的劳动者》为例
}

\section{Study on Classroom Design of "Study Book" Based on the Core Literacy of Political Discipline}

- Taking Workers in the New Era as An Example

\section{李亚莉}

Yali Li

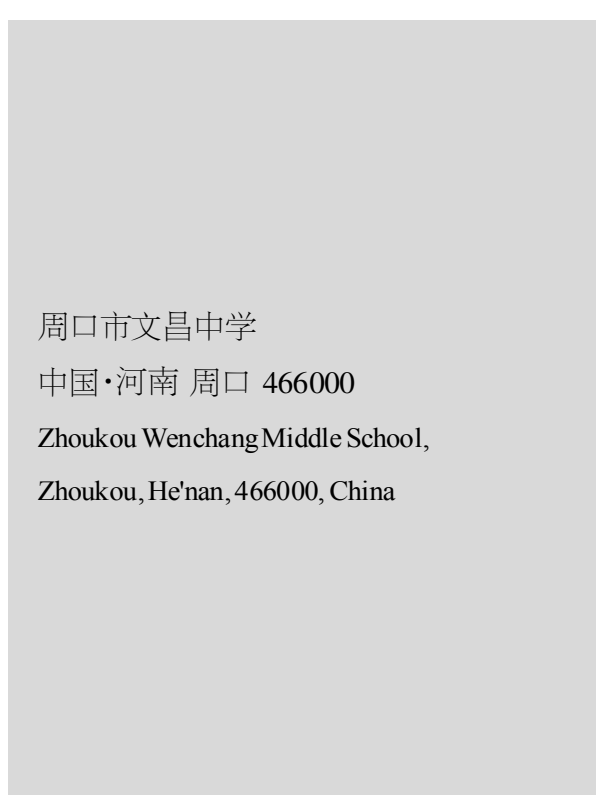

\section{1 引言}

高中《思想政治课程标准》中指明: 思想政治学科核心素 养是学生通过高中思想政治课的学习, 获得具有学科特点的 学业成就,包括政治认同、科学精神、法治意识和公共参与等 要素。其中政治认同决定着学生成长的方向,是根基;科学精 神是形成法治意识,实现公共参与的基本条件;法治意识是实 现公共参与的必要前提; 公共参与是政治认同、科学精神和法 治意识的行为表现。更新传统教学理念,转变“一言堂”的教学 模式,立足学生“学会”和“会学”的学本课堂,抓住关键问题的 解决, 锻炼学科思维能力, 是培养高中思想政治学科学生核心 素养的有效途径。笔者试以高中必修一经济生活《新时代的劳 动者》为例, 谈谈如何培养学生的政治学科核心素养。

\section{2 创设问题情境, 营造课堂探究氛围}

建构主义认为学习是学习者基于原有的知识经验生成意 义、建构理解的过程, 而这一过程常常是在社会文化互动中完

【作者简介】李亚莉(1983 ), 女, 河南周 $\square$ 人, 中学高级教师, 从事 教育领导与管理研究。
成的 ${ }^{[1]}$ 。同样, 学生的核心素养不是通过教师传授得来, 而是 学习者在一定的情境中建构获得。所以,教师要着眼于学生的 最近发展区, 巧设问题情境, 调动学生学习探究的积极性, 激 发学生学习的内驱力。笔者大胆创新, 把《新时代的劳动者》这 节课精心设计成一个话剧《阿啃求职记》, 以丰富多样的活动 形式展示对话,在思维碰撞中提升核心素养。

\section{3 设计多样活动,提升学科核心素养}

苏霍姆林斯基说: “让学生体验到一种自己在亲身参与掌 握知识的情感, 乃是唤起少年特有的对知识的兴趣的重要条 件。”这句话揭示了活动体验在学习中的重要作用。美国缅因 州的国家训练实验室研究成果表明, “做中学”或“实际演练” 的学习方式, 可以达到 75\%的学习保持率。爱德加·戴尔提出, 学习效果在 $50 \%$ 以上的,都是团队学习、主动学习或参与式学 习。笔者这节课着重引导学生开展探究实践活动, 让学生在活 动体验中提升核心素养。课前把全班 48 人分为 $\mathrm{A} 、 \mathrm{~B}$ 两班, 每 班四组, 每组六人。 $A$ 班的四个小组 $A 1 、 A 2 、 A 3 、 A 4$ 为表演组, 表演阿啃求职记的四幕。 $\mathrm{B}$ 班的四个小组 $\mathrm{B} 1 、 \mathrm{~B} 2 、 \mathrm{~B} 3 、 \mathrm{~B} 4$ 为解 说组, 解说表演组表演后提出的问题。抽到任务的小组在各小 
组学科长的带领下深入讨论, 创意设计, 精心准备, 精彩展演。 例如, 在展演第四幕《如此维权》时, 学生是这样表现的:

生 1 : 老板, 咱们已经三个月没有发工资了。这马上要到 春节了, 你要把这几个月的工资赶紧发了, 我好回家过年。

生 2: 阿啃啊, 咱们单位其他员工都没提意见呢, 你是业 绩比别人优秀, 还是资格比别人老啊? 你来跟我提要求? 公司 正赶上经济危机, 再等等吧, 估计过完年可能会好些。

生 3 :阿啃,怎么样,老板同意发工资了吗?

生 1 : 没有啊! 冬子,咱们怎么办? 没有钱哪有脸回家呢? 要不然咱俩假装跳楼, 吓唬老板, 让他给咱发工资怎么样?

生 3 : 行啊! 咱们去找一些工友, 人多力量大嘛!

生 4 : 有人跳楼啦! 快来看啊! 老板不发工资, 农民工跳楼 讨薪啦!

生 1 : 同志们, 老板居然这样都不理咱, 咱把老板押起来, 拉他去街上游行。

生 5: 我们组表演完毕, 请问“阿啃”的维权方式正确吗? 我们作为劳动者应该怎样维权呢?

教师设置 “如此维权” 这个问题情境, 引导学生参与话剧 的表演,注重对学生的公共参与素养的培养。学生以驱动性问 题进行了有效追问, 点燃其他学生深度讨论、合作探究的欲 望。在激烈的生生互动中学生的思维不断碰撞, 情感得以升 华。同学们在展讲和质疑中认识到阿啃维权方式的错误之处, 理性地分析问题并最终树立正确的观念, 采用合理又合法的 方式维护自己的合法权益。科学精神和法治意识的素养在轻 松的活动体验中得以提升。

\section{4 教师智慧导学,锻炼学科思维能力}

在学本课堂视域下, 课堂要由传统的知识传递型静态教 学向创新的知识建构型动态学习转变。教师要由过去的告知 教学转变为指导学生, 由过去的勤奋讲授转为智慧指导, 由过 去的权威管理转变为民主自律。课堂教学要逐步由“教师搭台 教师唱” 向“学生搭台学生唱”发展, 教师要想方设法让学生 “学会”和“会学”, 最终达到“教为了不教”的目的。

在《新时代的劳动者》这节学习方案设计中, 教师提前培 训了学生主持, 分好了 A、B 对抗班, 分配了表演组和演说组 两大阵营。教师从“编剧”的角度对教学内容进行细化, 把内容 编写成剧本, 分篇章、按流程、有时间计划地实现学习目的。教 师以“导演”的角色对整节课进行智慧设计, 引导学生身临其 境地参与其中, 从话剧表演到精彩展讲, 从提出问题到质疑点 评, 真正实现了“学生搭台学生唱”的课堂效果, 也处处体现了 教师的智慧导学。
在第二幕《艰难求职》中, $\mathrm{A}$ 同学饰演阿啃, 他只想找份 “工资又高又体面”的工作。 $\mathrm{B}$ 同学演示阿啃爷爷, 认为“别人 介绍的不靠谱, 就业就要靠政府”。C 同学饰演阿啃奶奶, 认为 “不管什么职业, 只要能稳定地干一辈子就行”。D 同学饰演阿 啃妈妈, 认为“一定要找到与自己专业对口的, 兴趣爱好一致 的工作”。 $\mathrm{E}$ 同学最后追问: “为什么阿啃这么难找工作? 他的 亲人们的建议对不对, 应该树立怎样的就业观? ”

问题设计是连接情境和知识的纽带, 是开启心智、激发思 维的起点。“智者问得巧”, 这个问题链的设计巧在从生活情境 中来又回到了生活情境中去, 设置了“对不对”的认知冲突, 启 发学生用科学精神和法治意识来思考分析, 最终达成政治认 同, 树立正确的情感、态度和价值观。4 个问题由浅入深, 层层 递进, 不断拓展延伸, 让学生学会调动知识, 理论联系实践。学 会辩证思维, 明辨是非曲直。

在解决最后一个问题, 提出合理化建议时, 个别学生的回 答有些天马行空, 这时笔者采用了“小纸条”“诱思引导”和“耳 语” 策略, 在教师的及时点拨和智慧导学的引领下, 学生的学 科思维能力得以锻炼和提升。

\section{5 构建多元评价, 注入持续发展动力}

衡量一节课成功与否的标准, 不在于教师讲得是否精彩, 而在于学生学的是否主动。在新高考的形式下,在学本课堂的 视域下,课堂评价的重点应该由过去“教师的教”转向“学生的 学”, 更加注重学生素养能力的提升和全面而有个性地发展。 法国教育学家第斯多惠曾说过: “教学艺术的本质不在于传 授, 而在于激励、唤醒和鼓舞。”教师富有激情的评价必然能调 动学生学习的积极性, 充分发挥学生的内在潜能。尤其在学本 课堂的初步实施阶段, 为了保护学生的自尊心, 树立学生的自 信心, 教师应该多采用激励性评价, 唤醒和鼓舞学生, 为学生 素养的培养搭建平台。

\section{6 结语}

学生的核心素养要想得到持续提升, 还必须构建多元评 价体系。搭建小组合作团队学习机制的平台, 重视学生的自我 评价、同伴评价、学科长评价、小组长评价和学术助理评价, 并 建立长效机制, 重视过程性评价与结果性评价相结合, 为政治 学科核心素养的提升提供机制保障, 为学生的能力发展注人 持续动力。

\section{参考文献}

[1]白美娟.基于地理核心素养培养的地理校本课程资源研究 [D]. 石家庄:河北师范大学, 2020 . 